\title{
Examen par le biais d'une restauration numérique d'une peinture de Sukhāvatī provenant de Dunhuang, conservée au Musée Guimet (MG. 17669)
}

Nobuyoshi Yamabe

\section{OpenEdition}

\section{Journals}

Édition électronique

URL : https://journals.openedition.org/annuaire-cdf/16509

DOI : $10.4000 /$ annuaire-cdf.16509

ISBN : 978-2-7226-0572-5

ISSN : 2109-9227

Éditeur

Collège de France

\section{Édition imprimée}

Date de publication : 30 décembre 2020

Pagination : 721-722

ISBN : 978-2-7226-0516-9

ISSN : 0069-5580

\section{Référence électronique}

Nobuyoshi Yamabe, «Examen par le biais d'une restauration numérique d'une peinture de Sukhāvatī provenant de Dunhuang, conservée au Musée Guimet (MG. 17669) », L'annuaire du Collège de France [En ligne], 118| 2020, mis en ligne le 01 avril 2021, consulté le 22 août 2022. URL : http://

journals.openedition.org/annuaire-cdf/16509; DOI : https://doi.org/10.4000/annuaire-cdf.16509 


\title{
EXAMEN PAR LE BIAIS D'UNE RESTAURATION NUMÉRIQUE D'UNE PEINTURE DE SUKHĀVATİ PROVENANT DE DUNHUANG, CONSERVÉE AU MusÉE GuIMET (MG. 17669)
}

\author{
YAMABE Nobuyoshi
}

Professeur à l'université Waseda, Tokyo (Japon)

Mots-clés : art, peinture, Asie

Conférence prononcée le 3 mai 2018 (invitation sur proposition des Pr Jean-Noël Robert et Frantz Grenet), disponible en audio sur le site internet du Collège de France : https://www.college-de-france.fr/site/jean-noel-robert/guestlecturer-2017-2018__.htm.

Le Sūtra sur la visualisation d'Amitāyus (Guan wuliangshou jing), qui, selon la tradition, a été traduit par Kālayaśas au début du V ve siècle, a été un texte bouddhique populaire en Asie de l'Est en raison de sa spectaculaire histoire et de ses descriptions colorées de Sukhāvatī (la Terre de Félicité) et du Bouddha Amitāyus.

Dans ce sūtra, le prince rebelle Ajātaśatru emprisonne son père, le Roi Bimbisāra. L'épouse de Bimbisāra, la Reine Vaidehī, est gravement préoccupée par cette situation et lui apporte en secret de la nourriture en prison. Lorsque Ajātaśatru apprend cela, il devient furieux et tue presque sa mère. Sa tentative, toutefois, est contrariée par ses ministres, mais Ajātaśatru envoie également sa mère en prison. Naturellement, la douleur de Vaidehī est sans limites. Pour consoler la reine éplorée, Śākyamuni apparaît miraculeusement devant elle, et Vaidehī lui demande de montrer à la reine un moyen de voir un monde sans chagrin. En réponse, Śākyamuni lui enseigne les méthodes pour visualiser la Terre de Félicité et Amitāyus. Les treize premières de ces méthodes consistent en des moyens de les visualiser, et les trois dernières, des façons de visualiser les trois types de personnes qui atteignent la renaissance dans la Terre de la Félicité.

$\mathrm{Au}$ vu des descriptions pittoresques de ce sūtra, il n'est pas surprenant que des scènes de ce sūtra aient souvent été représentées dans les peintures, et de nombreux exemples existent à Dunhuang ou en proviennent. L'un des problèmes ici est que, à l'exception de certains des premiers exemples, ces peintures montrent souvent des écarts importants de leur texte source, intitulé Le Sūtra sur la visualisation d'Amitāyus. L'examen attentif des sources textuelles et artistiques suggère fortement que ces écarts n'étaient pas fondés sur la version variante du texte mais plutôt causé par méprises des peintres. Apparemment, les peintres qui ont exécuté ces peintures n'ont pas lu le texte source, Le Sūtra sur la visualisation d'Amitāyus, mais ont simplement essayé de copier les peintures du même motif sans comprendre leur contenu. Ainsi, ils ont parfois mal interprété ce qu'ils voyaient, et les malentendus se sont accumulés au fil du temps. En outre, il semble que les scènes respectives de la peinture aient été traitées séparément et aient été librement transposées par les peintres. En conséquence, et de manière générale, les dernières peintures ont 
tendance à montrer plus de déviations par rapport au texte, à la fois dans l'arrangement des scènes et la représentation de scènes individuelles.

Le thème de cette conférence, MG. 17669, une peinture basée sur Le Sūtra sur la visualisation d'Amitāyus stockée dans le musée Guimet à Paris, et qui date de la fin du $\mathrm{VIII}^{\mathrm{e}}$ ou du début du $\mathrm{IX}^{\mathrm{e}}$ siècle, est un exemple intéressant à cet égard. En raison de son mauvais état de conservation, cette peinture n'a pas été beaucoup étudiée jusqu'à présent. Afin de faciliter l'examen, j'ai pris des photos haute résolution en lumière visible et en infrarouge de cette peinture avec la permission du musée, et j'ai utilisé la technologie de restauration numérique. J'ai ainsi pu obtenir des images plus claires. Les images restaurées montrent des similitudes avec Дх316 (fin du IX ${ }^{\mathrm{e}}$ ou début du $\mathrm{X}^{\mathrm{e}}$ siècle), un autre tableau conservé au musée de l'Ermitage (Saint-Pétersbourg). Dans les deux cas, les peintres n'ont probablement pas lu Le Sūtra sur la visualisation d'Amitāyus. Ils ont simplement suivi leur tradition artistique et effectué une copie à partir d'une peinture ou d'un croquis du même motif. De ces deux peintures, Дx316 semble être plus tardif d'une génération que MG. 17669. Les peintres de Дx316 doivent avoir placé MG. 17669, ou quelque chose de très similaire, en face d'eux et ont essayé de le copier. Cependant, ces peintres n'ont pas été suffisamment attentif, de sorte qu'ils ont introduit des erreurs supplémentaires dans leur travail.

Ces deux peintures s'écartent de manière significative du système du Sūtra sur la visualisation d'Amitāyus. Ce point est particulièrement évident dans le cas de Дx316, parce qu'il ne contient pas tous les éléments énumérés dans le sūtra. Même dans le cas de MG. 17669, les éléments décrits ne sont pas en accord avec ceux qui sont dans le sūtra. Ainsi, il est impossible de pratiquer la visualisation enseignée dans le sūtra en utilisant ces peintures. Par conséquent, il est hautement improbable que l'une de ces peintures ait été utilisée comme aide visuelle pour la pratique de la visualisation. 